\title{
Mortalidade de Pennisetum glaucum submetido a estresses associado
}

\author{
Lucena, L.R.R.; Leite, M.L.M.V.; Simões, V.J.L.P.; Almeida, M.C.R. and Izidro, J.L.S.
}

Universidade Federal Rural de Pernambuco. Brasil.

\section{PalaVRas chaVe adicIONAIS}

Estresse hídrico.

Estresse salino.

Modelagem.

Regressão.

Milheto.

\section{RESUMO}

A disponibilidade hídrica e qualidade da água nas regiões semiáridas são limitadas, e isto tem reduzido à produção agrícola nesta região. Neste contexto, a identificação de culturas mais tolerantes a estas condições torna-se necessário, pois pode auxiliar na obtenção de maiores produtividades. Objetivou-se avaliar a mortalidade de milheto submetido aos estresses hídrico e salino. O delineamento utilizado foi em blocos ao acaso, com quatro lâminas de irrigação com base na evapotranspiração da cultura - ETc (25, 50,75 e $100 \%$ ETc) e três níveis de salinidade $\left(0,03,2\right.$ e $\left.4 \mathrm{dS} . \mathrm{m}^{-1}\right)$, formando um esquema fatorial $4 \times 3$, com quatro repetições. Os resultados mostraram que a taxa de mortalidade em função do nível hídrico foi maior $(31,43 \%)$ para o menor nível e a menor $(20,0 \%)$ foi ao nível hídrico de $75 \%$, já a mortalidade em função da salinidade foi menor $(17,1 \%)$ quando utilizado o nível controle e maior $(42,86 \%)$ no nível máximo de salinidade. Após ajuste da taxa de mortalidade do milheto pelo modelo de regressão logístico verificou-se que a menor probabilidade da planta se manter viva ocorre no menor nível hídrico e maior salino, enquanto que a maior probabilidade é dado pelo maior nível hídrico e menor nível salino.

\section{Mortality of Pennisetum glaucum submitted to associated stresses}

\section{SUMMARY}

\section{ADDITIONAL KEYWORDS}

Azadirchata indica.

Pechuga de pollo de engorde.

Calidad sensorial.

Pérdidas de cocción y refrigeración.

\section{INFORMATION}

\section{Cronología del artículo.}

Recibido/Received: 14.09.2018

Aceptado/Accepted: 23.11.2018

On-line: 15.01 .2020

Correspondencia a los autores/Contact e-mail:

leandroricardo_es@@yahoo.com.br
Hydrical availability and water quality in semi-arid region are limited, and this has reduced agricultural production in this region. In this context, the identification of crops that are more tolerant to these conditions becomes necessary, since it can help in obtaining higher yields. The objective of this study was to evaluate the mortality rate of millet submitted to water and saline stresses. A randomized complete block design with four irrigation slides $(25,50,75$ and $100 \%$ of crop evapotranspiration) and three levels of salinity $\left(0.03,2\right.$ e $\left.4 \mathrm{dS} \cdot \mathrm{m}^{-1}\right)$, forming a $4 \times 3$ factorial scheme with four replicates. The results showed that the mortality rate as a function of the water level was higher (31.43\%) for the lower level and the lower $(20.0 \%)$ was for the water level of $75 \%$, since the mortality rate as a function of salinity was lower (17.1\%) when using the control level and higher (42.86\%) to maximum salinity level. After adjustment of millet mortality rate by logistic regression model, it was verified that the lowest probability of plant to remain alive is given by lowest hydrical level and highest saline level, while the highest probability is given by higher hydrical level and lower saline level.

\section{INTRODUÇÃO}

Os estresses hídrico e salino são os principais fatores que afetam a produção agrícola em regiões semiáridas, promovendo efeitos osmóticos e iônicos nos vegetais, entretanto as diversas espécies ou cultivares respondem de forma diferenciada quando expostas a essas condições (Yahmed et al. 2016, p. 36; Yamaguchi e Blumwald 2005, p. 615).

Diversos mecanismos morfológicos de convivência com os estresses hídrico e salino são utilizados pelas plantas: redução da área foliar e do número de folhas (Oliveira et al. 2011, p. 771), aumento na massa de raízes, encurtamento no ciclo de vida (Rhein et al. 2015, p. 330), ajustamento osmótico, através do acúmulo de compostos compatíveis (Khan et al. 2012, p. 746), aparato enzimático para eliminação das espécies reativas de oxigênio, como a dismutase do superóxido, catalase, peroxidase do ascorbato, e não enzimático, como o ácido ascórbico, glutationa, caratenóide, entre outros (Mittler 2002, p. 405).

Desta forma, as perdas de produtividade causadas devido à irregularidade das chuvas e à má qualidade das águas disponíveis para irrigação tornam a agricultura uma atividade muito vulnerável e de risco nestas regiões. Sob esta condição, o uso de irrigação com água subterrânea ou da captação das chuvas (Bezerra et al. 
2010, p. 1076) pode ser útil no sentido de viabilizar a produção agrícola.

No entanto, faz-se necessário levar em consideração que as águas subterrâneas de grande parte das regiões semiáridas do planeta possuem elevada concentração de sais (Silva et al. 2017, p. 2). Desse modo, o uso de espécies que apresentem maior resiliência às modificações ambientais torna-se necessário no sentido de aumentar a produtividade agrícola.

O milheto (Pennisetum glaucum) é uma espécie com metabolismo $\mathrm{C} 4$, tolerante ao déficit hídrico, sendo necessário, em média, $350 \mathrm{~mm}$ de água por ciclo (Ullah et al. 2017, p. 766; Singh et al. 2015, p. 55), podendo ser utilizada como alternativa de produção de grãos e pastagem cultivada em regiões semiáridas, devido à alta produção de biomassa e valor nutritivo (Santos et al. 2017, p. 119; Ghatak et al. 2016, p. 123). No que concerne à salinidade, o milheto apresenta tolerância moderada, apresentando reduções em mais de 70\% na germinação de sementes e crescimento de plântulas quando submetidas à concentração de $250 \mathrm{mM}$ de $\mathrm{NaCl}$ (Krishnamurthy et al. 2007, p. 179).

Estudos sobre o efeito da salinidade sobre o milheto, notadamente associados ao estresse hídrico, são escassos e fazem-se necessários, pois esta cultura apresenta grande potencial produtivo para regiões semiáridas. Diante do exposto, objetivou-se avaliar a mortalidade do milheto submetido aos estresses hídrico e salino.

\section{MATERIAL E MÉTODOS}

A pesquisa foi realizada na Universidade Federal Rural de Pernambuco, Unidade Acadêmica de Serra Talhada (UFRPE/UAST), Serra Talhada, Pernambuco, Brasil (Altitude: 429 m, latitude: $7^{\circ} 56^{\prime} 15^{\prime \prime} \mathrm{S}$ e longitude: $\left.38^{\circ} 18^{\prime} 45^{\prime \prime} \mathrm{O}\right)$. Conforme a classificação de Köppen, o clima é do tipo BSwh', denominado Semiárido, quente e seco, chuvas de verão-outono com pluviosidade média anual de $647 \mathrm{~mm}$ /ano e temperaturas do ar médias superiores a $25^{\circ} \mathrm{C}$ (Leite et al. 2017, p. 56).

O experimento foi instalado em blocos casualizados, no esquema fatorial $4 \times 3$, composto por quatro níveis de reposição de água, com base na evapotranspiração da cultura (ETc): 25\%.ETc, 50\%.ETc, 75\%.ETc e $100 \%$.ETc e três níveis de salinidade da água (0,03; 2 e 4 $\left.\mathrm{dS} . \mathrm{m}^{-1}\right)$, com quatro repetições, totalizando 48 unidades experimentais. De acordo com Ayers e Westcot (1999, p. 75), a água utilizada no tratamento controle $(0,03 \mathrm{dS}$ $\mathrm{m}^{-1}$ ) é classificada como $C 1$, sem nenhuma restrição de uso; a água de condutividade elétrica (CEa) $2 \mathrm{dS} \mathrm{m}^{-1}$ é classificada como $\mathrm{C} 3$, com alto risco de salinização; água de $\mathrm{CEa} 4 \mathrm{dS} \mathrm{m}^{-1}$ é classificada como $\mathrm{C} 4$, com risco de salinização considerado muito alto. Os níveis de salinidade na água de irrigação foram obtidos adicionando-se o sal cloreto de sódio $(\mathrm{NaCl})$ correspondente a 1,168 g/L e 2,337 g/L, respectivamente para os níveis de 2 e $4 \mathrm{dS} \mathrm{m} \mathrm{m}^{-1}$.

Foi utilizado um Cambissolo Háplico Ta Eutrófico, coletado na profundidade de $0-20 \mathrm{~cm}$, em seguida, homogeneizado e passado em peneira de 2,0 $\mathrm{mm}$ (Leite et al. 2017, p. 11). Posteriormente, cerca de $10 \mathrm{~kg}$ desse solo foi acondicionado em vasos plásticos com volume de $14,41 \mathrm{dm}^{3}$, perfurados no fundo e com uma camada de 2,0 cm de brita para drenagem da água de irrigação. Foi coletada uma amostra composta de solo para fins de análise de fertilidade, onde foi obtida a seguinte caracterização: pH (água) = 6,80; P (extrator Mehlich I) $=40,0 \mathrm{mg} \mathrm{dm}^{-3} ; \mathrm{K}^{+}=0,45 ; \mathrm{Ca}^{2+}=5,50 ; \mathrm{Mg}^{2+}=1,6 ; \mathrm{Al}=$ $0,0\left(\mathrm{cmol}_{\mathrm{c}} \mathrm{dm}^{-3}\right)$.

A cultivar de milheto (Pennisetum glaucum (L.) R. Br.) utilizada neste ensaio foi a IPA Bulk 1BF. A semeadura ocorreu no dia 28 de setembro de 2017, onde foram colocadas quatro sementes por vaso, bem distribuídas, a 2,0 cm de profundidade. Três dias após a semeadura ocorreu $100 \%$ de germinação. Todos os vasos foram mantidos na capacidade de campo, visando o estabelecimento das plantas. O desbaste ocorreu 10 dias após a emergência (DAE), retirando-se as plantas menores e mais fracas, deixando-se apenas duas plantas por vaso. A aplicação dos tratamentos deu-se início aos 15 DAE, com reposições de água a cada três dias. No total, as lâminas aplicadas foram de: 9,11 L, 18,23 $\mathrm{L}, 27,34 \mathrm{~L}$ e $35,74 \mathrm{~L}$, para os tratamentos de $25 \%$, 50\%, $75 \%$ e $100 \%$ ETc, respectivamente.

Para avaliação da mortalidade do milheto foi ajustado o modelo de regressão levando em consideração que a variável resposta (mortalidade) assume valores 0 e 1 , denominando a mortalidade como uma variável que apresenta distribuição binomial.

Se $Y$ tem distribuição binomial que assume valores 0 ou 1, e $\pi(x)$ é a probabilidade de sucesso dado o valor de uma determinada variável explicativa $x$, definimos o modelo de regressão logística por:

$$
\log \left\{\frac{\pi(\mathbf{X})}{1-\pi(\mathbf{X})}\right\}=\beta_{0}+\beta_{1} \mathrm{x}_{1}+\beta_{2} \mathrm{x}_{2}+\cdots+\beta_{\mathrm{k}} \mathrm{x}_{\mathrm{k}}+\varepsilon_{\mathrm{i}}
$$

em que $\mathbf{X}=\left(1, \mathrm{x}_{1}, \mathrm{x}_{2}, \ldots, \mathrm{x}_{\mathrm{k}}\right)^{\prime}$ contém os valores observados de variáveis explicativas.

O processo de estimação dos parâmetros é definido por máxima verossimilhança (Paula 2013, p. 25).

$$
\beta^{\mathrm{m}+1}=\left(\mathrm{X}^{\prime} \mathrm{V}^{\mathrm{m}} \mathrm{X}\right)^{-1} \mathrm{X}^{\prime} \mathrm{V}^{\mathrm{m}} \mathrm{z}^{\mathrm{m}}
$$

onde, $m=0,1, \ldots$, é o passo da iteração, $z_{i}=\eta_{i}+\frac{y_{i}-n_{i} \pi_{i}}{n_{i} \pi_{i}\left(1-n_{i} \pi_{i}\right)}$,

$$
\begin{aligned}
& , i=1,2, \ldots, n, y=\left(y_{1}, y_{2}, \ldots, y_{n}\right)^{\prime}, \\
& V=\operatorname{diag}\left\{n_{1} \pi_{1}\left(1-n_{1} \pi_{1}\right), n_{2} \pi_{2}\left(1-n_{2} \pi_{2}\right), \ldots, n_{k} \pi_{k}\left(1-n_{k} \pi_{k}\right)\right\} .
\end{aligned}
$$

Seja Y a mortalidade das plantas (variável resposta) que assume o valor 0- se a planta morreu e 1- se a planta esta viva; $x_{1}$ e $x_{2}$ as variáveis explicativas: nível hídrico e salino, respectivamente, logo o modelo proposto é definido por:

$$
\log \left\{\frac{\pi\left(\mathrm{x}_{1} ; \mathrm{x}_{2}\right)}{1-\pi\left(\mathrm{x}_{1} ; \mathrm{x}_{2}\right)}\right\}=\beta_{0}+\beta_{1} \mathrm{x}_{1}+\beta_{2} \mathrm{x}_{2}+\varepsilon_{\mathrm{i}}
$$


Tabela I. Mortalidade de Pennisetum glaucum em função da disponibilidade de água e dos níveis salinos (Mortality of Pennisetum glaucum due to the availability of water and saline levels).

\begin{tabular}{|c|c|c|c|c|}
\hline \multirow[t]{2}{*}{$\%$ da ETc } & \multicolumn{3}{|c|}{ Nível Salino (dS/m) } & \multirow[t]{2}{*}{ Total } \\
\hline & 0,03 & 2 & 4 & \\
\hline 25 & 4 & 3 & 4 & 11 \\
\hline 50 & 1 & 5 & 3 & 9 \\
\hline 75 & 0 & 3 & 4 & 7 \\
\hline 100 & 1 & 3 & 4 & 8 \\
\hline Total & 6 & 14 & 15 & 35 \\
\hline
\end{tabular}

A chance de uma planta se manter viva, fixado um determinado nível hídrico e variando a salinidade é definido por $\exp ^{\beta_{2}}$, enquanto que fixado um determinado nível salino e variando o hídrico a chance é definida por $\exp ^{\beta_{1}}$. Todas as análises foram realizadas utilizando o software R-project versão 2.13.1.

\section{RESULTADOS E DISCUSSÃO}

Quando avaliado a mortalidade em função do nível hídrico verifica-se que a maior taxa se deu ao menor nível 11 (31,43\%) e a menor sete $(20,0 \%)$ foi ao nível hídrico de $75 \%$, enquanto que a mortalidade em função dos diferentes níveis salinos foi menor quando utilizado o nível de salinidade controle seis $(17,1 \%)$ e maior no nível máximo de salinidade $15(42,86 \%)$, Tabela I.

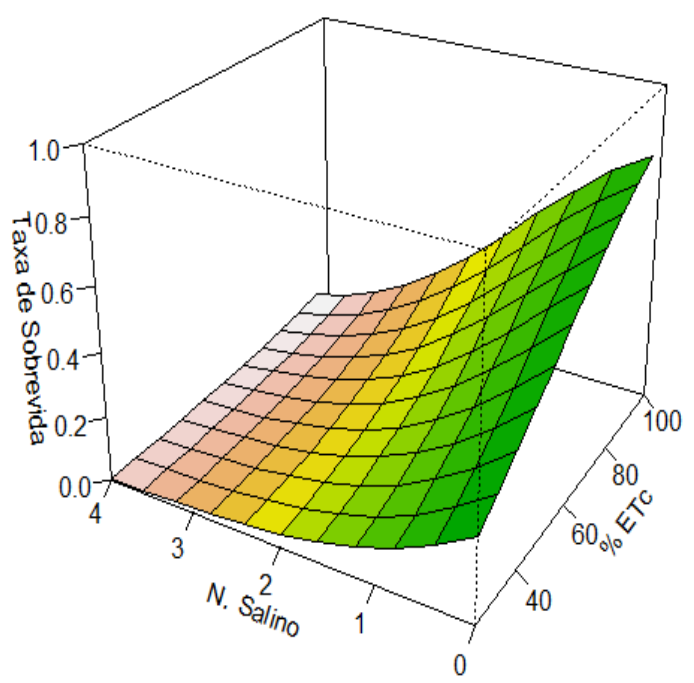

Figura 1. Taxa de sobrevida de Pennisetum glaucum em função da disponibilidade de água e dos níveis salinos (Pennisetum glaucum survival rate due to the availability of water and saline levels).
Amaral et al. (2003, p. 978) verificaram em diferentes cultivares de sorgo uma taxa de mortalidade variando de 0 a $20 \%$ para períodos de déficit hídricos curtos, já para períodos maiores de escassez hídrica esta taxa variou de 50 a $73 \%$ entre as linhagens de sorgo. Barreto et al. (2005, p. 30) verificaram em diferentes clones de Pennisetum purpureum Schum. e um hibrido de Pennisetum americanum uma taxa de mortalidade variando de 13,3 a $86,7 \%$, respectivamente quando submetidos estresse hídrico. Milbau et al. (2005, p. 503) observaram em diferentes espécies de gramíneas que após 20 dias de estresse hídrico a taxa de mortalidade variou de 80 a $100 \%$, respectivamente. Os resultados da presente pesquisa corroboram com os de Amaral et al. (2003, p. 978) e Barreto et al. (2005, p. 30), já que utilizando o menor nível hídrico e independente do grau de salinidade a taxa de mortalidade de foi de Pennisetum glaucum foi $31,43 \%$, enquanto que os achados de Milbau et al. $(2005$, p. 503) foram bastante superiores aos resultados da presente pesquisa, indicando uma maior tolerância a escassez hídrica do milheto quando comparadas as gramíneas.

Ashraf e McNeilly (1987, p. 16) submeteram a estresse salino cinco cultivares de milheto (Pennnisetum americanum) e observaram que a taxa de mortalidade variou de 23 a 32\%. Mori et al. (2011, p. 55) verificaram em feijão-vagem que a taxa de mortalidade ao final do experimento foi de $31,1 \%$ para o nível controle de salinidade e de 100\% para o maior nível salino. Estes resultados corroboram com os achados desta pesquisa, onde para o nível controle de salinidade obteve-se uma taxa de mortalidade de $17,14 \%$, enquanto que para o maior nível de salinidade a taxa foi de $42,86 \%$.

A fim de estimar a taxa de mortalidade do milheto (Pennisetum glaucum) em função dos diferentes níveis hídricos e salinos foi ajustado o modelo de regressão logístico conforme se observa abaixo:

$$
\mathrm{Y}=\pi\left(\mathrm{x}_{1} ; \mathrm{x}_{2}\right)=\frac{\exp ^{-1,98+0,0365 \times 1-1,0473 \times 2}}{1+\exp ^{-1,98+0,0365 \times 1-1,0473 \times 2}}
$$

Através deste modelo verifica-se que fixado um determinado nível de salinidade e a cada aumento de uma unidade no nível hídrico a chance da planta está viva é de 3,7\% maior, já fixado um determinado nível hídrico e a cada aumento de 
Tabela II. Estimativa, desvio padrão, estatística do teste e p-valor dos parâmetros do modelo (Estimation, standard deviation, test statistic and p-value of model parameters).

\begin{tabular}{lccc}
\hline Estimativa & Desvio padrão & Estatística do teste & $p$-valor \\
\hline$-1,98$ & 0,983 & $-2,052$ & 0,0365 \\
0,0365 & 0,017 & 2,138 & 0,0352 \\
$-1,0473$ & 0,353 & $-2,967$ & 0,0003 \\
\hline
\end{tabular}

uma unidade no nível salino a chance da planta continuar viva é $64,9 \%$ menor.

Na Tabela II, observam-se as estimativas dos parâmetros do modelo bem como os valores do desvio padrão, estatística do teste e p-valor associado para cada parâmetro estimado.

Supondo alguns cenários de nível hídrico e salino obtemos as probabilidades de sobrevida de Pennisetum glaucum, Tabela III.

Amaral et al. (2003, p. 978) verificaram que a taxa de sobrevida de diferentes linhagens de sorgo utilizando períodos de déficit hídricos longos variou de 27 a $50 \%$. Barreto et al. $(2005$, p. 30$)$ verificaram que a taxa de sobrevida em diferentes clones de Pennisetum purpureum Schum. e um hibrido de Pennisetum americanum submetidos a estresse hídrico variou de 13,3 a $86,7 \%$, respectivamente, no presente estudo verifica-se uma variação na taxa de sobrevida do milheto de $25,58 \%$ e de $37,28 \%$ quando utilizado os níveis hídricos mais baixos e o nível controle de salinidade. Milbau et al. (2005, p. 503) observaram uma taxa de sobrevida variando de 0 a $20 \%$ quando submeteram diferentes gramíneas a mais de 20 dias de escassez hídrica.

Ashraf e McNeilly (1987, p. 16) observaram variação na taxa de sobrevida dos cinco diferentes cultivares de milheto (Pennnisetum americanum) de 68 a $77 \%$ quando submeteram a estresse salino. Mori et al. (2011, p. 55) verificaram em feijãovagem que a taxa de sobrevida ao final do $45^{\circ}$ de experimento foi de $68,9 \%$ para o nível controle de salinidade e de $0 \%$ para o maior nível salino.

\begin{tabular}{|c|c|c|c|c|c|}
\hline \multicolumn{6}{|c|}{$\begin{array}{l}\text { Tabela III. Probabilidade de sobrevida de Pennise- } \\
\text { tum glaucum em função da disponibilidade de água } \\
\text { e dos níveis salinos (Probability of survival of Pennisetum } \\
\text { glaucum due to the availability of water and saline levels). }\end{array}$} \\
\hline \multirow{2}{*}{$\%$ da ETc } & \multicolumn{5}{|c|}{ Nível Salino (dS/m) } \\
\hline & 0,03 & 1 & 2 & 3 & 4 \\
\hline 25 & $25,58 \%$ & $10,77 \%$ & $4,06 \%$ & $1,46 \%$ & $0,51 \%$ \\
\hline 40 & $37,28 \%$ & $17,26 \%$ & $6,82 \%$ & $2,5 \%$ & $0,89 \%$ \\
\hline 50 & $46,13 \%$ & $23,10 \%$ & $9,5 \%$ & $3,57 \%$ & $1,28 \%$ \\
\hline 60 & $55,23 \%$ & $30,21 \%$ & $13,19 \%$ & $5,06 \%$ & $1,84 \%$ \\
\hline 75 & $68,08 \%$ & $42,81 \%$ & $20,80 \%$ & $8,43 \%$ & $3,13 \%$ \\
\hline 90 & $78,67 \%$ & $56,41 \%$ & $31,22 \%$ & $13,74 \%$ & $5,29 \%$ \\
\hline 100 & $84,16 \%$ & $65,08 \%$ & $39,54 \%$ & $18,67 \%$ & $7,45 \%$ \\
\hline
\end{tabular}

Observa-se que a menor probabilidade da planta se manter viva ocorre no menor nível hídrico e o máximo nível salino $(0,51 \%)$, enquanto que a maior probabilidade da planta se manter viva resulta da combinação do maior nível hídrico e menor nível salino $(84,16 \%)$, Tabela III e Figura 1.

Segundo Munns e Tester (2008, p. 651), o acúmulo de sais no solo promove redução no potencial hídrico do solo, induzindo a planta a gastar mais energia para continuar absorvendo água e/ ou realizar o fechamento estomático para manutenção do status hídrico, ocorrendo limitações na assimilação de $\mathrm{CO}_{2}$, o que pode contribuir para redução da atividade fotossintética, ocasionando menor desenvolvimento da planta, além de um maior estresse térmico devido à redução da transpiração. Em seguida, o acúmulo dos íons salinos no tecido vegetal causa intoxicação, e, consequentemente, morte dos tecidos vegetais, o que explica a menor probabilidade da planta se manter viva. A intensidade da toxidez irá depender do nível de tolerância da planta, tempo de exposição e quais íons estão sendo acumulados.

\section{CONCLUSÕES}

A mortalidade de Pennisetum glaucum pode ser ajustada através do modelo de regressão logístico. A maior taxa de mortalidade de Pennisetum glaucum resulta da associação do menor nível hídrico e o maior nível salino. O milheto apresenta tolerância moderada aos estresses hídrico e salino. Sob condições de restrição hídrica elevada e alta salinidade compromete-se em mais de $50 \%$ a sobrevivência das plantas de milheto, o que representa uma considerável redução da produtividade da cultura e consequentemente na oferta de forragem nas regiões Semiáridas.

\section{BIBLIOGRAFIA}

Amaral, SR, Lira, MA, Tabosa, JN, Santos, MVF, Mello, ACL, \& Santos, VF 2003, 'Comportamento de linhagens de sorgo forrageiro submetidas a déficit hídrico sob condição controlada', Pesquisa Agropecuária Brasileira, vol. 38, no. 8, pp. 973-79.

Ashraf, M \& Mcneilly, T 1987, 'Salinity effects on five cultivars/lines of pearl millet (Pennisetum americanum [L] Leeke)', Plant and Soil, vol. 103, no. 1, pp. 13-9.

Ayers, RS \& Westcot, DW 1999, 'A qualidade da água na agricultura', Campina Grande: UFPB, 153 p. (FAO. Estudos de Irrigação e Drenagem, 29).

Barreto, GP, Lira, MA, Santos, MVF, \& Dubeux Jr., JCB 2005, 'Produção de matéria seca e taxa de sobrevivência de clones de capim-elefante (Pennisetum purpureum Schum.) e um híbrido interespecífico com o milheto (Pennisetum americanum (L.) Leeke) submetidos a estresse hídrico', Pasturas Tropicales, vol. 27, no. 1, pp. 27-33

Bezerra, AKP, Lacerda, CF, Hernandez, FFF, Silva, FB, \& Gheyi, HR 2010, 'Rotação cultural feijão caupi/milho utilizando-se águas de salinidades diferentes', Ciência Rural, vol. 40, no. 5, pp. 1075-82. Ghatak, A, Chaturvedi, P, Nagler, M, Roustan, V, Lyon, D, Bachmann, G, Postl, W, Schröfl, A, Desai, N, Varshney, RK, \& Weckwerth, W 2016, 'Comprehensive tissue-specific proteome analysis of drought stress responses in Pennisetum glaucum (L.) R. Br. (Pearl millet)', Journal of Proteomics, vol. 143, no. 30, pp. 122-35. 
Khan, MIR, lqbal, N, Masood, A, \& Khan, NA 2012, 'Variation in Salt Tolerance of Wheat Cultivars: Role of Glycinebetaine and Ethylene', Pedosphere, vol. 22, no. 6, pp. 746-54.

Krishnamurthy, LR, Serraj, R, Rai, KN, Hash, CT, \& Dakheel, AJ 2007, 'Identification of pearl millet [Pennisetum glaucum (L.) R. Br.] lines tolerant to soil salinity', Euphytica, vol. 158, no. 1-2, pp. 179-88.

Leite, MLMV, Lucena, LRR, Sá Jr., EH, \& Cruz, MG 2017, 'Estimativa da área foliar em Urochloa mosambicensis por dimensões lineares', Revista Agropecuária Técnica, vol. 38, no. 1, pp. 9-16.

Milbau, A, Scheerlinck, L, Reheul, D, Cauwer, B, \& Nijis, I 2005, 'Ecophysiological and morphological parameters related to survival in grass species exposed to an extreme climatic event', Physiologia Plantarum, vol. 125, no. 4, pp. 500-12.

Mittler, R 2002, 'Oxidative stress, antioxidants and stress tolerance', Trends in Plant Science, vol. 7, no. 9, pp. 405-10.

Mori, M, Di Mola, I, \& Chiarandà, FQ 2011, 'Salt stress and transplant time in snap bean: growth and productive behavior', International Journal of Plant Production, vol. 5, no. 1, pp. 49-64.

Munns, R \& Tester, M 2008, 'Mechanisms of Salinity Tolerance', Annual Review of Plant Biology, vol. 59, no. 1, pp. 651-81.

Oliveira, FA, Carrilho, MJSO, Medeiros, JF, Maracajá, PB, \& Oliveira, MKT 2011 , 'Desempenho de cultivares de alface submetidas a diferentes níveis de salinidade da água de irrigação', Revista Brasileira de Engenharia Agrícola e Ambiental. vol. 15, no. 8, pp. 771-77.

Paula, GA 2013, 'Modelos de Regressão com apoio computacional', Universidade de São Paulo, 403 p.
Rhein, AFL, Cruz, FJR, Ferraz, RLS, \& Santos, DMM 2015, 'Crescimento radicular e pigmentos clorofilianos em duas forrageiras submetidas a níveis crescentes de $\mathrm{NaCl}^{\prime}$, Científica, vol.43, no.4, pp.330-335.

Santos, KC, Magalhães, ALR, Silva, DKA, Araújo, GGL, Fagundes, GM, Ybarra, NG \& Abdalla, AL 2017, 'Nutritional potential of forage species found in Brazilian Semiarid region', Livestock Science, vol. 195, pp. 118-24.

Silva, JRI, Souza, RMS, Santos, WA, Almeida, AQ, Souza, ES, \& Antonino, ACD 2017, 'Aplicação do método de Budyko para modelagem do balanço hídrico no semiárido brasileiro', Scientia Plena, vol. 13, no. 10, pp. 109908.

Singh, J, Reddy, PS, Reddy, CS, \& Reddy, MK 2015, 'Molecular cloning and characterization of salt inducible dehydrin gene from the $\mathrm{C} 4$ plant Pennisetum glaucum', Plant Gene, vol. 4, pp. 55-63.

Ullah, A, Ahmad, A, khaliq, T, \& Akhtar, J 2017, 'Recognizing production options for pearl millet in Pakistan under changing climate scenarios', Journal of Integrative Agriculture, vol. 16, no. 4, pp. 762-73.

Yamaguchi, T \& Blumwald, E 2005, 'Developing salt-tolerant crop plants: challenges and opportunities', Trends Plant Sciences. vol. 10, no. 12, pp. 615-20.

Yahmed, JB, Oliveira, TM, Novillo, P, Quinones, A, Forner, MA, Salvador, A, Froelicher, Y, Mimoun, MB, Talon, M, Ollitrault, P, \& Morillon, $R$ 2016, 'A simple, fast and inexpensive method to assess salt stress tolerance of aerial plant part: Investigations in the mandarin group', Journal of Plant Physiology, vol. 190, pp. 36-43. 